$\underline{\text { Drug Research }}$

Pharmacopsychiatry

$\underline{\text { Synfacts }}$

$\underline{\text { Synlett }}$

-

Synthesis

Related Books

Chemistry

Share / Bookmark

CiteULike Delicious

Planta Med 2014; 80 - P1L20

DOI: $10.1055 / \mathrm{s}-0034-1394678$

\title{
Xanthenedione derivatives, new promising acetylcholinesterase inhibitor agents
}

\author{
A Seca $\stackrel{1}{2} \stackrel{2}{ }, \mathrm{~S}$ Leal $\stackrel{2}{ }, \mathrm{D}$ Pinto $\stackrel{2}{ }, \mathrm{M}$ do Carmo Barreto $\stackrel{1}{\underline{1}} \underline{\underline{3}}, \mathrm{~A}$ Silva $\stackrel{2}{2}$ \\ - ${ }^{1}$ DCTD, University of Azores, Rua Mãe de Deus, 9501 - 801 Ponta Delgada, Portugal \\ - ${ }^{2}$ Department of Chemistry \& QOPNA, University of Aveiro, 3810 - 193 Aveiro, Portugal \\ - ${ }^{3}$ Centro de Investigação em Recursos Naturais, 9501 - 801 Ponta Delgada, Portugal \\ - $\underline{\text { Congress Abstract }}$
}

Acetylcholinesterase inhibitors (AChEIs) are employed in medicine mostly for correcting the effects of insufficient levels of acetylcholine [1]. Xanthones are a class of secondary metabolites associated with important pharmacological properties, being some of its derivatives AChEIs [2]. Xanthenedione derivatives are not widely spread in nature but their synthesis and bioactivities evaluation is still a hot topic. Following our interest in the synthesis of biologically active compounds, several xanthene-1,9(2H)-diones $(2 a-2 f)$ were synthesized by simple and efficient methodologies from (E,E)-3-cinnamoyl-5-hydroxy-2-styrylchromones (Scheme 1) [3] and their acetylcholinesterase activity evaluated by a modification of the Ellman's method [4]. The results (Table 1) showed that variations in the substitution and hydroxylation pattern seem to be important for their activity, being the xanthenedione bearing a catechol unit the most potent AChEI, even more active than galantamine, an AChEI alkaloid used clinically in early stages of Alzheimer's disease. SAR studies showed that the presence of hydroxyl 3-aryl and 4-benzylidene moieties is essential for the activity. Furthermore xanthenedione $2 c$ showed a combination of partially competitive and non-competitive inhibition, while xanthenedione $2 e$ shows an almost pure competitive type inhibition. The most active xanthenediones $2 e$ and $2 c$ present zero violations of Lipinski's 'rule of five' and xanthenedione $2 c$ combine higher AChE activity with good oral bioavailability properties (TPSA $<140 \AA 2$ ). The results suggest that they may be 
excellent templates for drugs to be used in the prevention and treatment of neurodegenerative diseases.

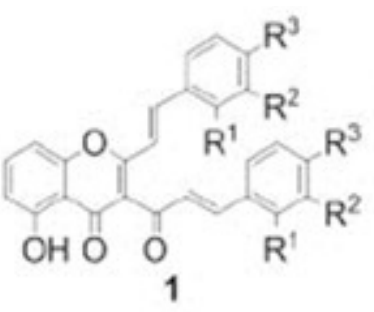

1a) $R^{1}, R^{2}, R^{3}=H$

1b) $R^{1}, R^{2}=\mathrm{H}_{1} \mathrm{R}^{3}=\mathrm{CH}_{3}$

1c) $\mathrm{R}^{1}, \mathrm{R}^{2}=\mathrm{H}, \mathrm{R}^{3}=\mathrm{OCH}_{3}$

1d) $\mathrm{R}^{1}, \mathrm{R}^{2}=\mathrm{H}, \mathrm{R}^{3}=\mathrm{Cl}$

1e) $\mathrm{R}^{1}=\mathrm{H}, \mathrm{R}^{2}, \mathrm{R}^{3}=\mathrm{OCH}_{3}$

1f) $\mathrm{R}^{1}=\mathrm{Cl}, \mathrm{R}^{2}, \mathrm{R}^{3}=\mathrm{H}$

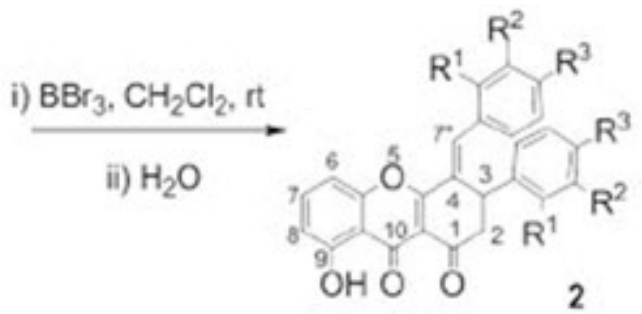

2a) $R^{1} \cdot R^{2} \cdot R^{3}=H$

2b) $\mathrm{R}^{1}, \mathrm{R}^{2}=\mathrm{H}, \mathrm{R}^{3}=\mathrm{CH}_{3}$

2c) $R^{1}, R^{2}=H, R^{3}=\mathrm{OH}$

2d) $\mathrm{R}^{1}, \mathrm{R}^{2}=\mathrm{H}, \mathrm{R}^{3}=\mathrm{Cl}$

2e) $R^{1}=H, R^{2}, R^{3}=\mathrm{OH}$

2f) $\mathrm{R}^{1}=\mathrm{Cl}, \mathrm{R}^{2}, \mathrm{R}^{3}=\mathrm{H}$

Tab. 1: Acetylcholinesterase inhibitory effect of xanthenediones (2) and some intermediates (1).

\begin{tabular}{|c|c|}
\hline Compounds & $\begin{array}{l}\text { Anti-AChE } \\
I C_{50}(\mu M \pm S D, n=4)\end{array}$ \\
\hline $1 \mathrm{a}$ & $>381$ \\
\hline $1 \mathrm{c}$ & $122 \pm 2.1$ \\
\hline $2 a$ & $>381$ \\
\hline $2 b$ & $>355$ \\
\hline $2 c$ & $41.1 \pm 6.1$ \\
\hline $2 \mathrm{~d}$ & $>325$ \\
\hline $2 c$ & $31.0 \pm 0.09$ \\
\hline $2 \mathrm{f}$ & $>325$ \\
\hline Galanthamine & $211.8 \pm 9.5$ \\
\hline
\end{tabular}


Acknowledgements: Thanks are due to FCT, EU, QREN, FEDER and COMPETE, for funding the QOPNA research unit (project PEst-C/QUI/UI0062/2013; FCOMP-01 - 0124-FEDER-037296) and the Portuguese National NMR Network and also Azores University and FRC/Azores for funding CIRN.

Keywords: Xanthones, xanthene-1,9(2 H)-diones, acetylcholinesterase inhibitors, synthesis

References:

[1] Houghton, PJ, Ren, Y, Howes, MJ. Acetylcholinesterase inhibitors from plants and fungi. Nat. Prod. Rep. 2006; 23: $181-199$.

[2] Brígida R. Pinho, BR, Ferreres, F, Valentão, P, Andrade, PB. Nature as a source of metabolites with cholinesterase-inhibitory activity: an approach to Alzheimer's disease treatment. J. Pharm. Pharmacol. 2013; 65: $1681-1700$.

[3] Pinto, DCGA, Seca, AML, Leal, SB, Silva, AMS, Cavaleiro, JAS. A novel short-step synthesis of new xanthenedione derivatives from the cyclization of 3-cinnamoyl-2-styrylchromones. Synlett $2011 ; 2005-2008$.

[4] Barreto MC, Arruda M, Rego E, Medeiros JS, Rainha N. Cell-free assays. In: Barreto MC, Simões N. Determination of Biological Activities. A Laboratory Manual, N. Universidade dos Açores, Ponta Delgada; 2012: $65-81$.

Top of Page

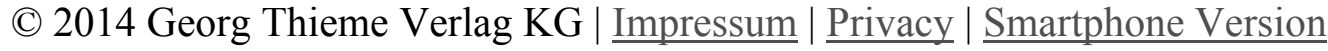

